DOI 10. 18307/2017. 0325

(C) 2017 by Journal of Lake Sciences

\title{
洞庭湖水面面积与城陵矶水位之间的绳套关系
}

\author{
柯文莉 ${ }^{1,2}$, 陈成忠 ${ }^{1}$, 吉红霞 $^{2}$, 陈 秘 $^{1,2}$, 刘元波 $^{2 * *}$ \\ ( 1 : 湖北师范大学, 黄石 435000$)$ \\ (2: 中国科学院南京地理与湖泊研究所, 南京 210008)
}

\begin{abstract}
摘 要: 洞庭湖是我国第二大淡水湖, 与长江连通, 在防洪抗旱和湿地生态保护等方面具有重要的现实意义. 采用 Terra/ MODIS L1B 遥感数据, 提取了 2000-2012 年洞庭湖水面面积, 结合同期城陵矶水位观测数据, 建立了城陵矶水位与洞庭 湖水面面积的绳套关系曲线. 分析结果表明: 2000-2012 年间,洞庭湖水面面积呈现总体减少的趋势; 在季节上表现为规 律性的涨落, 具有明显的涨 (4-6月)-丰 (7-9 月) - 退 (10-12 月) - 枯 (1-3 月) 的水文特征; 在空间格局上表现为由湖 体中心向外扩张, 随后由外向湖体中心逐渐收缩的变化过程; 洞庭湖水面面积与城陵矶水位之间具有较高的相关性, 但 不同时期的相关系数存在一定的差异: 枯水期二者相关性较低, 丰水期相关性最高, 涨水期和退水期相关性较高; 这种差 异与各个时期的主导因素不同有关, 长江来水对枯水期、丰水期的绳套关系影响较大, 其中东洞庭湖最为明显; 不论丰水 年 (2002 年) 或干旱年 (2011 年), 洞庭湖水面面积变化与城陵矶水位之间的相关性均较高. 研究结果对于深人认识江湖 关系的宏观复杂性、长江中下游地区以及洞庭湖水域洪涝灾害的预防和治理都具有积极的意义.
\end{abstract}

关键词: 长江;洞庭湖;江湖关系;水位一面积曲线;水文遥感

\section{A loop-like relationship between water surface area of Lake Dongting and water level at Chenglingji, the Yangtze River}

\author{
KE Wenli ${ }^{1,2}$, CHEN Chengzhong ${ }^{1}$, JI Hongxia ${ }^{2}$, CHEN Mi $^{1,2} \&$ LIU Yuanbo ${ }^{2 * *}$ \\ (1: Hubei Normal University, Huangshi 435000, P.R. China) \\ (2: Nanjing Institute of Geography and Limnology, Chinese Academy of Sciences, Nanjing 210008, P.R. China)
}

\begin{abstract}
Lake Dongting is the second largest freshwater lake in China, directly connected to the Yangtze River. It has significance of practical effects on flood control, drought prevention and wetland conservation. This study addresses spatial-temporal variation in water surface area of Lake Dongting and its relationship with water level at Chenglingji of the Yangtze River. Water surface area were extracted from multi-temporal images of the Terra/MODIS (moderate-resolution imaging spectroradiometer) for the years 2000-2012. In combination of water level data of Chenglingji, a loop-like relationship was explored between the lake water surface area and the water level. Our results show that the lake area decreased from 2000 to 2012, with a strong seasonal variation in terms of rising (April-June), flooding (July-September), retreating (October-December) and drying (January-March) periods. The inundated area displays a seasonal change of spatial pattern with expansion from lake center to its maximum bounds during February-August and contraction from its maximum bounds to lake center during September-January. The lake water surface has a good correlation with the water level at Chenglingji and the correlation coefficient varies in seasons with the minimum value for drying period, the maximum for flooding period, and relatively high values for rising and retreating periods. The variation is probably related to the difference in controlling factors in different time periods. The Yangtze River has a relatively large impact on the loop-like relationship in drying season and flooding season, especially for the east Lake Dongting, which is the case even for high-and low-water years. Our findings offer an insight into the complexity of river-lake relationship and provide an important basis for flooding prevention in Lake Dongting and the mid-and lower-reaches of Yangtze River.
\end{abstract}

* 国家重点基础研究发展计划“973”项目(2012CB417003) 和中国科学院南京地理与湖泊研究所“一三五”战略发展 规划项目 (NIGLAS2012135001) 联合资助. 2016-04-03 收稿;2016-08-01 收修改稿. 柯文莉 (1993 ), 女, 硕士 研究生;E-mail: kewenli5825@163.com.

** 通信作者;E-mail: ybliu@ niglas.ac.cn. 
Keywords: Yangtze River; Lake Dongting; river-lake relationship; area-water level curve; hydrologic remote sensing

洞庭湖是我国第二大淡水湖, 也是长江中游重要的吞吐湖泊, 长江上游来水经松滋口、太平口和藕池口 进人洞庭湖, 同时洞庭湖还承接了湘、资、沅、澧“四水”, 经调蓄后由城陵矶注人长江, 与长江之间形成了复 杂的江湖关系 ${ }^{[1-2]}$. 作为长江中游的通江湖泊, 洞庭湖的存在和稳定对于拦截长江上游来水, 分蓄长江中游 洪水,缓解长江下游洪涝灾害等具有重要的现实意义 ${ }^{[3-4]}$.

近年来, 长江中游地区洪旱灾害频繁, 洞庭湖区水文特征发生了一定的变化, 长江与洞庭湖之间的关系 也随之不断演变 ${ }^{[1,5-9]}$. 另一方面 2003 年 6 月三峡工程开始蓄水运行, 这意味着江湖关系又进入了新一轮的 变化与调整过程 ${ }^{[8,10-12]}$. 陈进等 ${ }^{[13]}$ 从洞庭湖与长江之间的演变过程分析江湖互通对于稳定河势与防洪的作 用; 赖锡军等 ${ }^{[14]}$ 选取三峡工程典型的蓄水过程, 模拟了洞庭湖水情的时空变化; 李景保等 ${ }^{[15]}$ 运用洞庭湖区 域与长江干流相关控制站点 1951-2010 年实测水文数据, 从不同时间尺度分析了江湖水体交换能力的演变 特征及其对三峡运行的响应; Huang 等 ${ }^{[16]}$ 根据洞庭湖区域水文情势, 分析了该区域水文干旱的因果关系, 并 利用神经网络模型评估三峡工程流量调节对洞庭湖地区干旱的影响; Lai 等 ${ }^{[17]}$ 利用水动力模型, 分析了 2006- 2011 年因三峡水量调节直接引起的长江中下游水位变化分量; 宋求明等 ${ }^{[18]}$ 结合洞庭湖水面面积与 湖区水文站水位数据, 通过建立两者的拟合曲线, 分析了洞庭湖水面面积与湖区不同水位站水位之间的关 系, 其中包括城陵矶水位站. 众多学者从不同角度探讨了江湖关系, 但是已有的关于洞庭湖水面面积与城陵 矶水位关系的研究 ${ }^{[18-21]}$, 主要将不同时期洞庭湖水面面积与城陵矶水位关系笼统地进行分析, 建立统一的 水位-面积关系曲线,并未系统地刻画不同时期水位一面积绳套的关系曲线. 然而, 受“三口”、“四水”不同时 期来水的影响, 洞庭湖水情特征异常复杂, 在涨、退、丰、枯各个时期的水位一面积绳套关系可能是不同的. 系 统地刻画不同时期水位一面积的绳套关系, 对于深刻认识洞庭湖水面面积变化与长江之间的关系, 长江中游 水系及洞庭湖流域旱涝灾害、水资源季节性短缺等一系列水问题,具有重要的实践意义.

鉴于此, 本文采用卫星遥感数据和水面面积提取方法, 重建近十年来洞庭湖水面面积变化过程; 结合水 位观测数据建立洞庭湖水面面积与城陵矶水位之间的水位一面积绳套关系曲线; 在分析洞庭湖水面面积的 时空变化规律基础上,揭示洞庭湖水面面积与城陵矶水位关系在不同季节、不同典型水位年份的变化特征, 深化对于江湖关系宏观复杂性的认识.

\section{1 研究区和数据}

\section{1 研究区概况}

洞庭湖 $\left(28^{\circ} 44^{\prime} \sim 29^{\circ} 35^{\prime} \mathrm{N}, 111^{\circ} 53^{\prime} \sim 113^{\circ} 05^{\prime} \mathrm{E}\right)$ 位于长江中游荆江南岸. 地跨湖南、湖北两省, 属于亚热 带湿润季风气候, 热量丰富, 降水充足, 降水季节集中, 降水量年际变化较大 ${ }^{[22]}$. 洞庭湖水域辽阔, 是我国第 二大淡水湖, 也是亚洲最大的内陆湿地保护区, 被誉为 “拯救世界濒危珍稀鸟类的主要希望地”, 并于 1992 年列入《世界重要湿地名录》, 其中东洞庭湖湿地还是国家级湿地自然保护区, 是全球范围内公认的生态保 护区, 在国际上具有十分重要的地位 ${ }^{[23]}$. 城陵矶水文站位于洞庭湖出口与长江汇合口上游 $3.5 \mathrm{~km}$, 是洞庭湖 出口河段水文控制站 ${ }^{[24]}$. 城陵矶水位为 $31.5 \mathrm{~m}$ (1956 年黄海基面) 时, 湖长 $143 \mathrm{~km}$, 最大湖宽 $30 \mathrm{~km}$, 平均湖 宽 $17 \mathrm{~km}$, 最大水深 $18.67 \mathrm{~m}$, 平均水深 $6.69 \mathrm{~m}$, 湖泊面积 $2625 \mathrm{~km}^{2}$, 相应蓄水量为 $167 \times 10^{8} \mathrm{~m}^{3}$, 湖区由东洞庭 湖、南洞庭湖、西洞庭湖 3 部分组成, 呈近似“U”字形 ${ }^{[22]}$ (图 1).

\section{2 数据来源与处理}

本文采用源于 NASA ( National Aeronautics and Space Administration) 网站 (http://ladsweb. nascom. nasa. gov/) 的中低分辨率 Terra/MODIS L1B 数据. MODIS 即中分辨率成像光谱仪, 是搭载在 EOS-AM1 系列卫星 上的观测仪器之一, 它拥有 36 个波谱波段, 分布在 $0.4 \sim 14.4 \mu \mathrm{m}$ 的电磁波谱范围内 ${ }^{[25]}$. 文中采用的 Terra/ MODIS L1 B 数据包括 MODI02_HKM、MODI02_QKM 以及 MODI03. 用 MRT(MODIS Reprojection Tool) 软件对 下载好的 MODIS 数据进行处理,首先选取提取水体所需的 MODI02_HKM b1 波段和 MODI02_QKM b1 波段,然 后用 MODI03 对 MODI02 数据进行几何纠正, 再将投影全部转换为通用横轴墨卡托投影. 由于 MODI02_HKM 和 MODI02_QKM 的空间分辨率不同, 用 ENVI 将 $500 \mathrm{~m}$ 空间分辨率的绿色波段全部重采样为 $250 \mathrm{~m}$. 然后根 


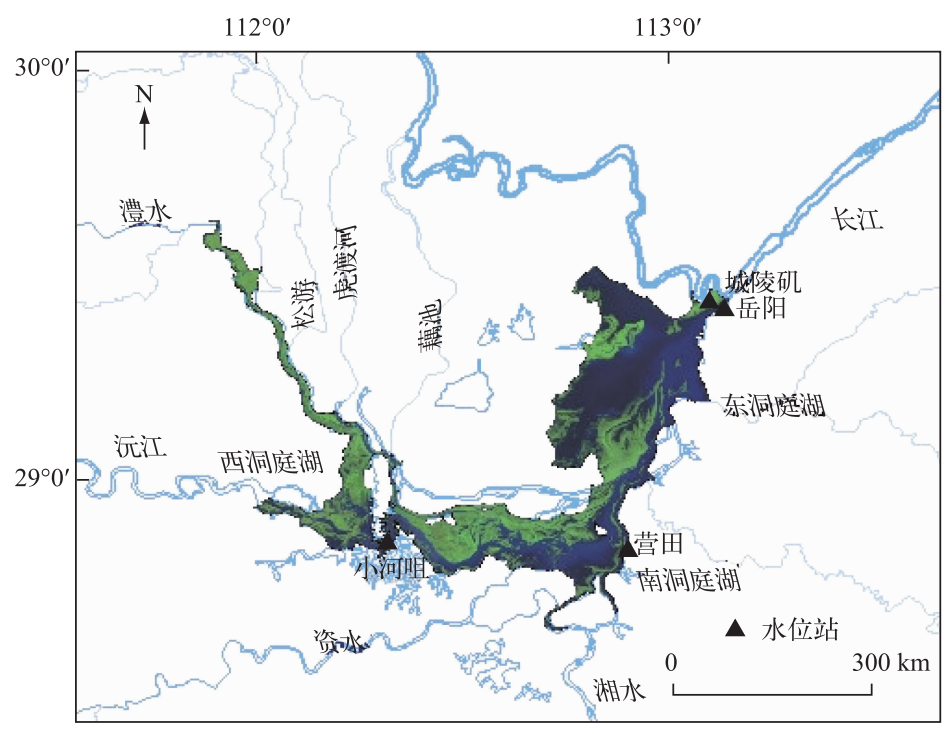

图 1 洞庭湖地理位置

Fig. 1 Geographical location of Lake Dongting

据湖区边界进行裁剪,得到可用的研究区影像. 采用源于美国地球资源 (http://glovis.usgs.gov/) 的中高分辨 率 Landsat 数据, 检验 MODIS 数据提取水体面积的精度. Landsat 卫星是世界上第一颗对地观测卫星, 它包含 多种类型的传感器, 分别是反束光摄像机 (RBV)、多光谱扫描仪 (MSS)、专题成像仪 (TM) 和增强专题成像 仪 $\left(\mathrm{ETM} 、 \mathrm{ETM}^{+}\right)$, 可以全面监测地球陆地资源 ${ }^{[26-27]}$. 本文抽取 Landsat 数据中绿波段 b2 和近红外波段 b4 进 行水体提取运算,所选择的 Landsat TM 影像日期为: 2000 年 11 月 1 日、2001 年 4 月 13 日、2001 年 7 月 28 日、 2001 年 8 月 27 日、2001年 9 月 5 日、2001 年 9 月 14 日、2002 年 3 月 30 日、2002 年 7 月 11 日、 2002 年 7 月 12 日、 2003 年 3 月 25 日. 遥感数据及其特征见表 1 . 城陵矶的逐日水位数据来自湖南省水利厅水文信息 网 (http://www.hnwr.gov.cn/) , 时间序列覆盖 2000-2012 年.

表 1 遥感数据及其特征

Tab.1 Remote sensing date and their features

\begin{tabular}{cccccc}
\hline & 卫星影像 & 空间分辨率 $/ \mathrm{m}$ & 光谱分辨率 $/ \mu \mathrm{m}$ & 波段 & 影像数量 \\
\hline \multirow{2}{*}{ EOS-Terra } & MODIS02_HKM & 500 & 绿: $0.54 \sim 0.57$ & 4 & 385 \\
& MODIS02_QKM & 250 & 近红外: $0.84 \sim 0.88$ & 2 & \\
\multirow{3}{*}{ Landsat } & TM & 30 & 绿: $0.52 \sim 0.60$ & 2 & \\
& ETM $^{+}$ & 30 & 近红外: $0.76 \sim 0.90$ & 4 & 10 \\
& OLI & 15 & 全色: $0.50 \sim 0.68$ & 8 & \\
\hline
\end{tabular}

\section{2 水面面积提取方法}

为研究 2000-2012 年洞庭湖水面面积的时空变化, 选取 MODIS 影像共 385 景, 用 NDWI-ISODATA 法求 得本文所需的洞庭湖水面面积数据.

$N D W I$ ( Normalized Difference Water Index) 指数是 McFeeters ${ }^{[28]}$ 在 $N D V I$ ( Normalized Difference Vegetation Index) 的基础上提出的,利用水体在绿波段反射强和植被在近红外波段反射强建立反差, 以突出水体抑制植 被等地物信息. 理想情况下, $N D W I$ 为正值时表示地面有水、雨雪覆盖; $N D W I$ 为 0 时表示地面覆盖为岩石或 裸土等; NDWI 为负值时表示有植被覆盖 ${ }^{[29]}$. 但实际情况受多种因素的影响, 使得区分水体与其他地物的阈 
值往往不为 0 , 要通过直方图人为判断确定阈值.

$N D W I$ 法虽然可以较好地提取水体, 但是受人为选取阈值的影响较大. ISAODATA 法 (Iterative Self-Organizing Data Analysis Technique Algorithm, 迭代自组织数据分析算法) 是通过引人参数而不断进行分裂与合 并的非监督分类算法 ${ }^{[30]}$. ISAODATA 法只考虑到同类像元在光谱特征上的高度相似性, 仅需要确定初始的 分类类别, 通过调整样本所属类别完成样本的聚类分析, 并使用类别的合并和分裂机制, 受主观因素的影响 较小. 因此对遥感影像采用 NDWI 与 ISAODATA 法结合的方法可以避免人为确定阈值的影响, 提高水面面 积的提取精度 ${ }^{[31]}$.

为了验证所求水面面积数据的精确性, 选取分辨率较高的 Landsat TM 影像, 采用相同的提取水体方法 NDWI-ISODATA 法, 对 Landsat TM 数据和 MODIS 数据提取水体面积的结果进行对比, 来检验 MODIS 数据的 提取结果. 然后通过建立城陵矶水位与洞庭湖水面面积的线性拟合曲线以及水位-面积关系曲线, 从时空角 度分析洞庭湖水面面积变化与城陵矶水位的关系.

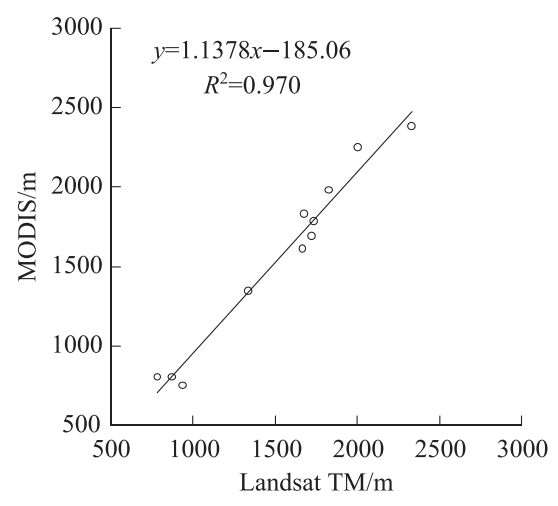

图 2 MODIS 与 Landsat TM 提取面积对比

Fig.2 Comparison of extracted water area from MODIS and Landsat TM

\section{3 结果与讨论}

\section{1 基于 MODIS 影像提取的水面面积精度}

以 Landsat TM 数据提取的水体面积作为标准值, 将 MODIS 数据提取的水体面积与其比值作为衡量精度的大小. 与 Landsat 数据对应的 10 景 MODIS 数据提取的水体面积的精度 均在 $80 \%$ 以上,均方根误差为 $122.54 \mathrm{~km}^{2}$. 将 MODIS 数据和 Landsat 数据提取的水体面积线性拟合发现, 二者相关系数达 到 0.970 , 精度较高 ( 图 2).

\section{$3.22000-2012$ 年洞庭湖水面面积的季节及年际变化规律}

对 2000-2012 年洞庭湖月均水面面积最大值、最小值以 及均值进行统计分析发现, 月平均面积最大值 $\left(2049.73 \mathrm{~km}^{2}\right.$ ) 出现在 7 月, 最小值 $\left(570.29 \mathrm{~km}^{2}\right)$ 出现在 1 月, 变化速率为 $123.29 \mathrm{~km}^{2} /$ 月; 每月面积最大值在 $800 \mathrm{~km}^{2}$ 以上, 且其最大值 $\left(2749.19 \mathrm{~km}^{2}\right)$ 出现在 7 月, 最小值 $\left(838.06 \mathrm{~km}^{2}\right)$ 出现在 1 月, 变化速率为 $159.26 \mathrm{~km}^{2}$ /月; 每月面积最小值在 $300 \mathrm{~km}^{2}$ 以上, 其最小值 $\left(311.56 \mathrm{~km}^{2}\right)$ 出现在 12 月, 最大值 $\left(1349.75 \mathrm{~km}^{2}\right)$ 出现在 7 月, 变化速率为 $86.52 \mathrm{~km}^{2} /$ 月. 洞庭湖水面面积在 11 月至次年 4 月较小, 在 5-10 月较大, 其中 7-9 月维持在 $2000 \mathrm{~km}^{2}$ 左右, 7 月最大、 1 月最小, 7 月为洞庭湖的丰水月, 1 月为洞庭湖的枯 水月.洞庭湖水面面积具有季节性特征: $1-3$ 月份面积较小, 无明显增加趋势; $4-6$ 月份, 洞庭湖区面积增长 较快; 在 7-8 月份面积持续增长达到最大值; 9-12 月面积开始逐渐减少. 洞庭湖水面面积年内变化呈现规 律性涨落, 具有明显的涨 (4-6 月) - 丰 (7-9 月) - 退 (10-12 月) - 枯 (1-3 月) 的水文节律 (图 3A).

对 2000-2012 年洞庭湖年际水面面积最大值、最小值以及均值进行统计分析发现, 洞庭湖水面面积均 值逐渐减小, 年平均面积最小值 $\left(781.58 \mathrm{~km}^{2}\right.$ ) 出现在 2006 年, 最大值出现在 2000 年, 大于 $1500 \mathrm{~km}^{2}$, 变化速 率为 $62.34 \mathrm{~km}^{2} / \mathrm{a}$. 年际水面面积最大值在 $1800 \mathrm{~km}^{2}$ 以上, 其最大值 $\left(2749.19 \mathrm{~km}^{2}\right)$ 出现在 2000 年, 最小值 $\left(1806.25 \mathrm{~km}^{2}\right)$ 出现在 2011 年, 变化速率为 $72.53 \mathrm{~km}^{2} / \mathrm{a}$; 年际水面面积最小值在 $300 \mathrm{~km}^{2}$ 以上, 其最小值 $\left(311.56 \mathrm{~km}^{2}\right)$ 出现在 2004 年, 最大值 $\left(555.81 \mathrm{~km}^{2}\right)$ 出现在 2000 年, 变化速率为 $18.79 \mathrm{~km}^{2} / \mathrm{a} .2000-2012$ 年 年际面积最大值变化速率较大, 最小值变化速率较小. 2000 、2002 年洞庭湖水面面积较大, 为洞庭湖丰水年; $2006 、 2011$ 年水面面积较小, 为洞庭湖枯水年 (图 3B).

\section{$3.32000-2012$ 年洞庭湖水面面积的空间变化过程}

洞庭湖水面面积由丰到枯的变化表现为: 从 8 月至次年 1 月由外向湖体中心逐渐减小,东洞庭湖减少最 多,南洞庭湖次之,西洞庭湖减少最小 (图 4A). 由枯水期到丰水期的变化具体表现为: $2-8$ 月水面面积从湖 体中心向外逐渐增长, 到 7 或 8 月达到最大值, 其中东洞庭湖面积增长最大, 南洞庭湖次之, 西洞庭湖面积增 长最小 (图 4B). 可以发现洞庭湖水面面积年内变化呈现规律性涨落, 具有季节性变化特征, 表现为丰水期 

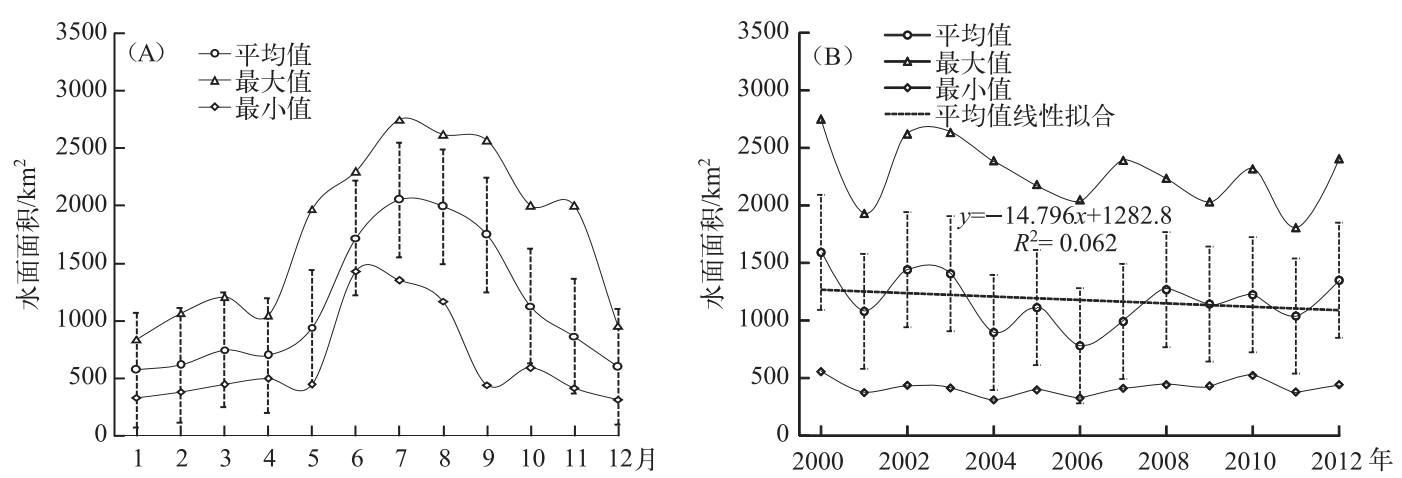

图 $32000-2012$ 年洞庭湖月平均面积 (A) 和年平均面积 (B)

Fig.3 Monthly mean area (A) and annual mean area (B) of Lake Dongting from 2000 to 2012

(7-9 月) 平均水面面积在 $1746.82 \mathrm{~km}^{2}$ 以上,水面面积广阔; 枯水期 (1-3 月) 平均水面面积在 $442.63 \mathrm{~km}^{2}$ 以下, 仅存几条带状水域. 东洞庭湖水面面积在涨水期 (4-6 月) 增长最大, 平均每月增长 $246.4 \mathrm{~km}^{2}$, 退水期 (10-12 月) 水面面积减小最多, 平均每月减少 $270.3 \mathrm{~km}^{2}$, 最能体现洞庭湖 “涨水为湖、退水为洲” 的特点.
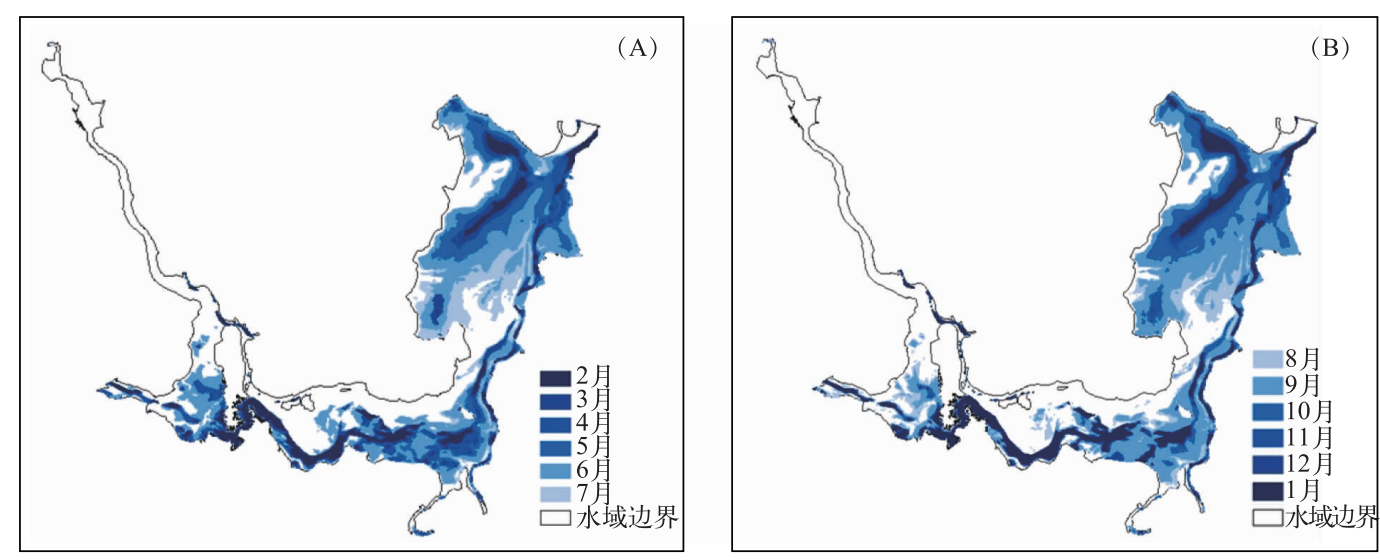

图 4 洞庭湖水面面积的空间格局变化过程

Fig.4 Changes of spatial distribution of Lake Dongting area

\section{4 不同季节洞庭湖水面面积与城陵矶水位之间的关系}

通过城陵矶水位与洞庭湖水面面积数据拟合 (图 5A), 发现 2000-2012 年洞庭湖水面面积与城陵矶水 位相关性较高, 相关系数为 0.878 , 水位变化 $1 \mathrm{~m}$, 水面面积变化 $172.77 \mathrm{~km}^{2}$. 城陵矶水位低于 $24 \mathrm{~m}$ 或高于 30 $\mathrm{m}$ 时, 洞庭湖水面面积变化不大. 城陵矶水位介于 $24 \sim 30 \mathrm{~m}$ 时, 洞庭湖水面面积变化较大. 对 2000-2012 年 洞庭湖水面面积与城陵矶水位月平均值做线性拟合, 得到二者的绳套关系曲线, 相关系数为 0.926 . 洞庭湖 水面面积与城陵矶水位的绳套关系曲线呈现为 3 个环形相连接, 每 4 个月份形成一个小环形 $(1 、 2 、 3$ 月以及 12 月为一环, $4 、 5 、 10$ 月以及 11 月为一环, $6 、 7 、 8$ 月以及 9 月为一环). 一般情况下, 线性拟合可以得到月平 均水位一面积呈单值的直线, 即最高水位对应最大水面面积 ${ }^{[32]}$. 而洞庭湖具有涨丰枯退的水情, 因此水位一 面积呈现多值关系. 在枯水期尽管水位、水面面积均较小, 但是水面面积大于拟合水面面积的值,曲线偏向 上; 在涨水期,水面面积小于拟合面积,曲线偏向下; 在丰水期, 水面面积达到最大值,最大水面面积与最大 水位基本是对应的,水位与面积的相关性很高,水面面积大于拟合面积,曲线偏向上; 在退水期,水面面积逐 渐下降, 小于拟合面积, 曲线相对偏下 (图 5B). 对 2000-2012 年东洞庭湖水面面积与城陵矶水位月平均值 做线性拟合, 得到二者的绳套关系曲线, 相关系数为 0.937 . 东洞庭湖水面面积的变化同样具有涨 - 丰 - 枯 - 退 
的特点. 将东洞庭湖水面面积与城陵矶水位的绳套关系曲线和洞庭湖水面面积与城陵矶水位的绳套关系曲 线进行对比,发现两条曲线相似,均为 3 个环形相连接,并且两条曲线在枯水期、涨水期、丰水期、退水期均 有这样一种现象: 水位相同时,水面面积存在差异;水面面积相同时,对应不同的水位. 但东洞庭湖曲线两端 的环形较小, 水面面积变化及城陵矶水位变化较小, 中间的环形较大,也即在涨水期、退水期东洞庭湖水面 面积及城陵矶水位变化较大 (图 5C).

在枯水期和退水期, 洞庭湖水面面积为 $600 \mathrm{~km}^{2}$ 时, 对应的城陵矶水位差距达到 $2.1 \mathrm{~m}$, 同样面积条件 下, 退水期城陵矶水位高于枯水期水位 (图 5B). 城陵矶是洞庭湖水泄人长江的唯一出口, 并且城陵矶水位 由洞庭湖与长江交汇口处的水位决定, 而退水期长江来水量大于枯水期 ${ }^{[15,33-34]}$. 因此洞庭湖水面面积相同 时,退水期城陵矶水位高于枯水期水位. 在涨水期和退水期城陵矶水位都为 $25.5 \mathrm{~m}$ 时, 退水期洞庭湖水面面 积比涨水期水面面积大 $330 \mathrm{~km}^{2}$. 从图 5 中可以发现, 涨水期城陵矶水位在 5 月左右达到 $25.5 \mathrm{~m}$, 此时 “四 水” 进人汛期, 西洞庭湖、南洞庭湖水面面积增长较多, 东洞庭湖水面面积增长较少, 洞庭湖水面面积仍然较 小 (图 4). 退水期城陵矶水位在 10 月左右降至 $25.5 \mathrm{~m}$, 此时洞庭湖水面面积受 “三口”、“四水” 来水共同影 响, 西洞庭湖、南洞庭湖水面面积减少较多, 东洞庭湖水面面积减少较少, 洞庭湖水面面积仍然较大 (图 4). 因此在城陵矶水位相同时, 涨水期洞庭湖水面面积比退水期的水面面积小. 在涨水期和丰水期水面面积 $\left(1700 \mathrm{~km}^{2}\right)$ 相同的情况下, 城陵矶水位差可达到 $1.1 \mathrm{~m}$. 丰水期洞庭湖水面面积在 9 月左右为 $1700 \mathrm{~km}^{2}$, 长 江流域汛期到达尾期, 来水量依然较大, 此时 “三口” 对洞庭湖的水量补给较多, 洞庭湖对长江水量的补给能 力强, 城陵矶水位高, 而涨水期洞庭湖水面面积在 6 月左右达到 $1700 \mathrm{~km}^{2}$, 长江流域开始进人汛期, 长江来 水量逐渐增大,但没有丰水期长江来水量大 ${ }^{[15,34]}$. 因此在同一面积情况下,丰水期城陵矶水位高于涨水期 水位.

以上分析表明,长江来水量对枯水期、丰水期洞庭湖水面面积与城陵矶的绳套关系影响较大, 东洞庭湖 面积的大小对涨水期、退水期洞庭湖水面面积与城陵矶水位的绳套关系存在一定的影响.

洞庭湖由东洞庭湖、南洞庭湖、西洞庭湖 3 部分组成, 其中东洞庭湖是洞庭湖的出水口, 并且水面面积 远大于南洞庭和西洞庭湖. 对比洞庭湖及东洞庭湖在涨、丰、枯、退 4 个时期的线性拟合结果 (图 6), 发现洞 庭湖整个湖区水面面积与城陵矶水位的相关系数在枯水期为 0.291 , 涨水期为 0.700 , 丰水期为 0.853 , 退水期 为 0.744 . 东洞庭湖水面面积与城陵矶水位的相关系数在枯水期为 0.138 , 涨水期为 0.773 , 丰水期为 0.794 , 退水期为 0.763 . 在枯水期, 洞庭湖整个湖区以及东洞庭湖的水面面积与城陵矶水位的相关性均较差. 而在 丰水期, 不论是整个湖区还是东洞庭湖的水面面积都与城陵矶水位的相关性较高, 并且是涨、丰、枯、退 4 个 时期中相关性最高的时期. 在涨水期和退水期, 全湖区和东洞庭湖的水面面积与城陵矶水位的相关性都较 高, 达到 0.7 以上. 这说明洞庭湖水面面积变化与城陵矶水位具有一定的相关性, 但是二者在不同时期的相 关性有差异.

枯水期是 “三口” 对洞庭湖补给水最少和洞庭湖对长江补给水最少的时期, 但 “四水” 仍有较大水量汇 入洞庭湖, 枯水期洞庭湖、东洞庭湖水面面积主要受 “四水” 来水影响 ${ }^{[15,34]}$. 城陵矶水位由洞庭湖与长江交 汇口处的水位决定, 尽管在枯水期, 湖泊对长江补给能力相对较强, 但长江的过水能力远大于洞庭湖, 城陵 矶水位主要受制于长江水位变化 ${ }^{[33,35]}$. 东洞庭湖距离 “四水”较远, 距离长江较近, 水面面积受长江的影响 显著, 但是枯水期长江来水极少. 因此洞庭湖水面面积与城陵矶水位的相关性较低, 东洞庭湖水面面积与城 陵矶水位的相关性更低. 涨水期“三口” 人湖水量逐渐增加, “四水” 因进人主汛期人湖水量为全年最大值, 洞庭湖、东洞庭湖水面面积受 “四水” 来水影响较大, 受 “三口” 来水影响次之 ${ }^{[15,34]}$. 此时, 城陵矶水位受洞庭 湖出水和长江来水共同影响, 洞庭湖、东洞庭湖水面面积与城陵矶水位相关性都较高. 丰水期是长江干流主 汛期, “三口” 对洞庭湖的补给能力增大, 亦即长江泄人洞庭湖水量最多及洞庭湖泄人长江水量最多的季节, 此时 “四水” 主汛期已过, 洞庭湖、东洞庭湖水面面积受 “三口” 影响较大, 且长江来水及洞庭湖出水都较大, 城陵矶水位高 ${ }^{[15,34]}$. 因此洞庭湖、东洞庭湖水面面积与城陵矶水位的相关性在丰水期最高. 退水期长江中游 汛期结束, “三口”、四水来水量逐渐减少, 此时洞庭湖、东洞庭湖水面面积受 “三口”、“四水” 来水共同影响, 但湖泊对长江补给能力仍然较强, 此时, 城陵矶水位主要受长江来水影响, 受洞庭湖出水影响次之 ${ }^{[15,34]}$. 因 此退水期, 洞庭湖、东洞庭湖水面面积与城陵矶水位的相关性也较高. 长江来水量对枯水期、丰水期洞庭湖 

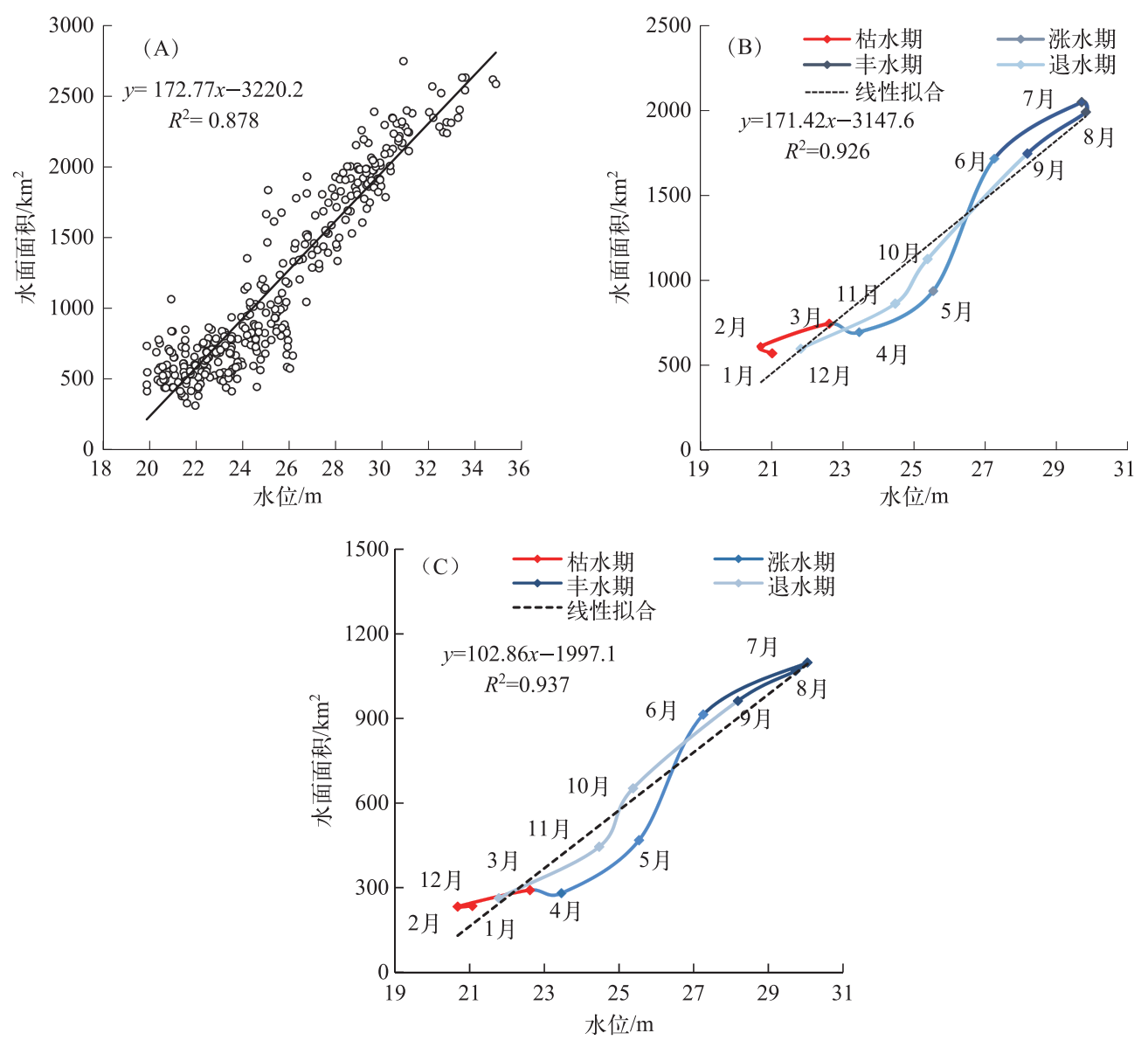

图 5 洞庭湖水面面积与城陵矶水位之间的关系 $(A)$, 洞庭湖 $(B)$ 和东洞庭湖 $(\mathrm{C})$ 水面面积与城陵矶水位的绳套关系曲线

Fig.5 The regression analysis between the water level of Chenglingji and the area of Lake Dongting (A), loop-like curve of the water level of Chenglingji and areas of Lake Dongting ( B) and East Lake Dongting( C)

水面面积与城陵矶相关性的影响较大, 对东洞庭湖水面面积与城陵矶相关性的影响更为显著.

从洞庭湖整个湖区看,在枯水期、涨水期、丰水期、退水期,城陵矶水位变化 $1 \mathrm{~m}$,鄱阳湖水面面积分别变 化 76.338、175.51、167.22 和 $155.67 \mathrm{~km}^{2}$. 从东洞庭湖区看,在枯水期、涨水期、丰水期、退水期,城陵矶水位变 化 $1 \mathrm{~m}$,东洞庭湖水面面积分别变化 $23.418 、 114.28 、 82.503$ 和 $100.88 \mathrm{~km}^{2}$ (图 6). 可以发现,在枯水期, 水位 变化 $1 \mathrm{~m}$, 不论是洞庭湖整个水域还是东洞庭湖水域, 面积变化都较小, 水面面积变化与城陵矶水位相关性 低, 且枯水期城陵矶水位大都小于 $24 \mathrm{~m}$. 在涨水期、退水期, 不论是洞庭湖整个水域还是东洞庭湖水面面积 变化都较大,且涨水期城陵矶水位变化 $1 \mathrm{~m}$ 时洞庭湖水面面积变化大于丰水期. 而涨水期水位大致为 $24 \sim$ $26 \mathrm{~m}$, 丰水期水位一般情况下高于 $30 \mathrm{~m}$. 也即城陵矶水位低于 $24 \mathrm{~m}$ 或高于 $30 \mathrm{~m}$ 时, 洞庭湖面积变化不大. 城陵矶水位介于 $24 \sim 30 \mathrm{~m}$ 时, 洞庭湖水面面积变化较大. 东洞庭湖与洞庭湖水面面积变化规律一致, 同时东 洞庭湖水面面积与城陵矶水位的相关性在退水期和涨水期高于整个湖区, 可以发现东洞庭湖水面面积的变 化对涨水期、退水期洞庭湖整个湖区水面面积与城陵矶水位的相关性有所影响. 

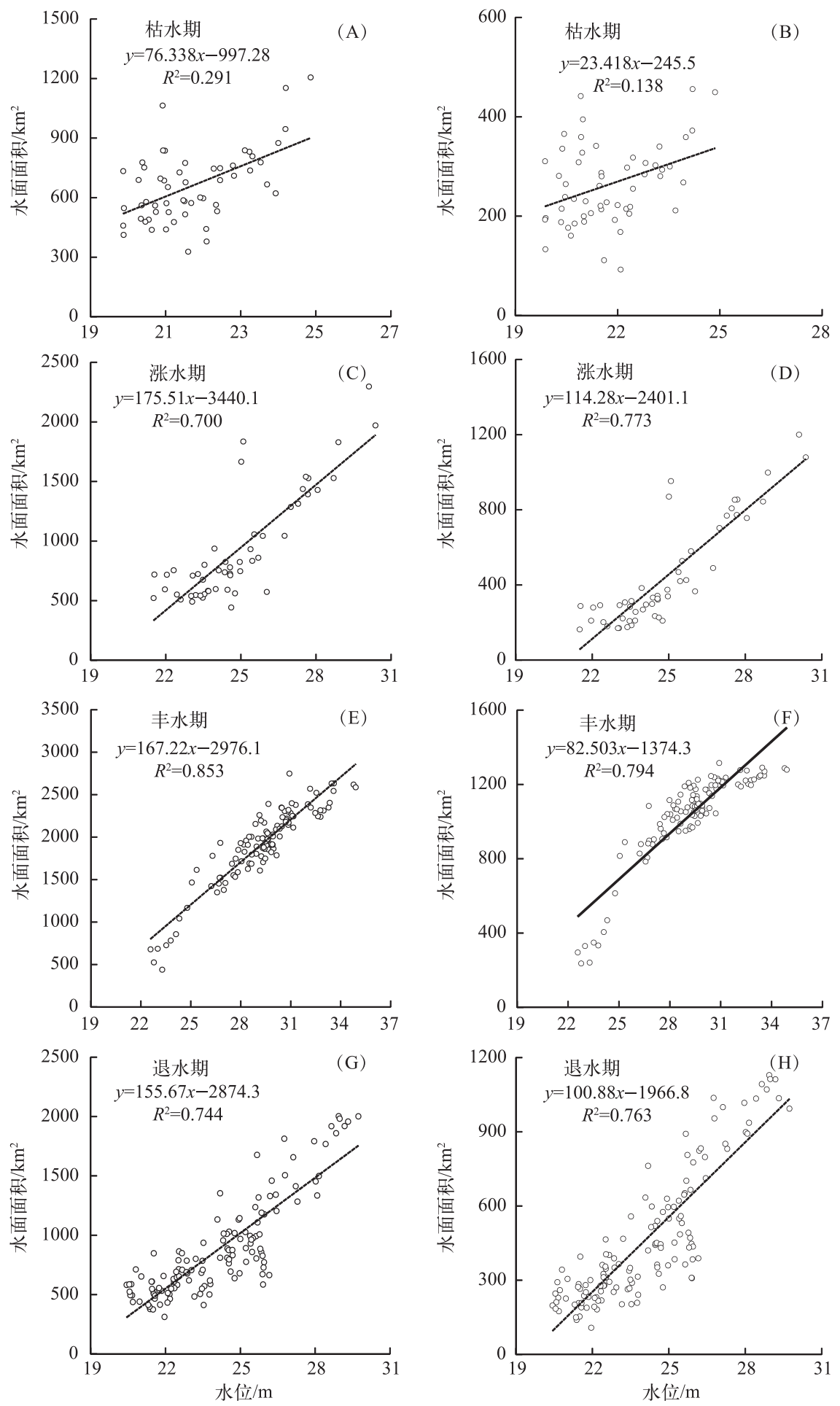

图 6 不同时期洞庭湖 $(A 、 C 、 E 、 G)$ 、东洞庭湖 $(B 、 D 、 F 、 H)$ 水面面积与城陵矶水位的回归分析

Fig.6 Regression analysis between the water level of Chenglingji and the areas of Lake Dongting ( A, C, E, G) and east Lake Dongting ( B , D , F , H) in different periods 


\section{4 典型水文年份的水面面积与城陵矶水位关系的变化过程}

2002 年是洞庭湖的丰水年, 8 月由于湘、资、沅、澧“四水” 齐涨, 长江也形成了特大洪峰,承接“四水”、连 通长江的洞庭湖水域出现了历史第 4 高水位, 发生了特大洪涝灾害 ${ }^{[36]}$. 如图 7 所示, 2002 年 5-9 月,洞庭 湖水面面积月平均值都在 $1500 \mathrm{~km}^{2}$ 以上, 城陵矶水位月平均值都在 $30 \mathrm{~m}$ 以上. 将 2002 年城陵矶月平均水 位与洞庭湖月平均水面面积拟合, 得到二者的绳套关系曲线, 相关系数为 0.940 , 城陵矶水位变化 $1 \mathrm{~m}$, 洞庭 湖水面面积变化 $169.48 \mathrm{~km}^{2}$. 1- 4 月,城陵矶水位升高,但洞庭湖水面面积基本没增长. 这一时期, “三口”、 “四水”来水较少, 洞庭湖水面面积较小, 但湖水对长江有所补给, 因此城陵矶水位有所上 升 $^{[15,34]} \cdot 4-8$ 月, 洞庭湖水面面积迅速增大, 城陵矶水位迅速上升. 这是由于 “三口” “四水” 逐渐进人汛期, 来水增大, 洞庭 湖水面面积迅速增大, 城陵矶水位受洞庭湖出水与长江来水的共同影响, 也迅速升高 ${ }^{[15,34]} .8-9$ 月, 城陵矶 水位持续上升, 但洞庭湖水面面积变化较小. 这一时期, “四水” 齐涨, 与长江洪峰相遇, 因此洞庭湖水面面积 变化并未同往年同期一样开始逐渐减小, 水面面积依然较大, 城陵矶水位受长江洪峰影响, 水位持续上 升 $^{[36]}$. 9-12 月, 洞庭湖水面面积逐渐减少, 城陵矶水位也逐渐下降. 这是由于 “三口” “四水” 汛期结束, 洪 水退去, 因此洞庭湖水面面积逐渐减小, 城陵矶水位也逐渐下降. 2011 年是洞庭湖的干旱年, 湖区累积降水 比历年同期偏少至 50\% 60\% , 最严重时水面面积不及正常年份的 $1 / 3$, 本该“涨水为湖” 的时节却出现 “退 水为洲” 的水情景观, 给湖区生态环境带来了极大影响 ${ }^{[37]}$. 如图 7 所示, 2011 年除 6-8 月以外,其他月份洞 庭湖水面面积月平均值在 $800 \mathrm{~km}^{2}$ 以下, 城陵矶水位月平均值在 $25 \mathrm{~m}$ 以下. 将 2011 年城陵矶月平均水位与
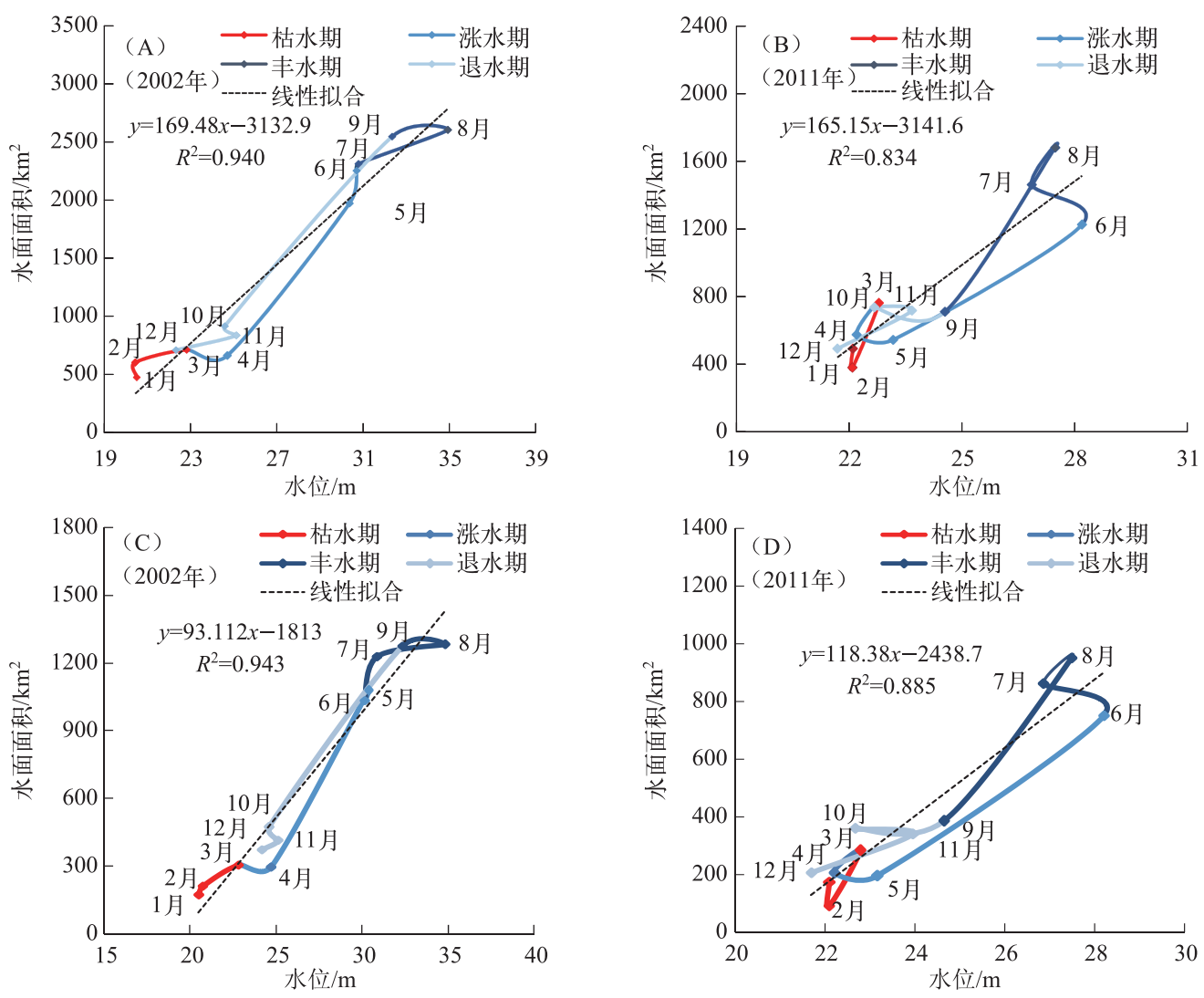

图 72002 和 2011 年洞庭湖 (A、B) 和东洞庭湖 (C、D) 水面面积与城陵矶水位的绳套曲线

Fig.7 Loop-like curves of the water level of Chenglingji and the areas of Lake Dongting (A,B) and east Lake Dongting( C,D) in 2002 and 2011 
洞庭湖月平均水面面积进行拟合,得到二者的绳套关系曲线,相关系数为 0.834 ,城陵矶水位变化 $1 \mathrm{~m}$, 洞庭 湖水面面积变化 $165.15 \mathrm{~km}^{2}$. 1-5 月, 城陵矶水位有所上升, 洞庭湖水面面积变化较小. 这一时期, 长江中下 游降水持续偏小,较常年同期偏少 $53.1 \%$, “四水” 来水量较常年同期偏少 $50 \%$, 洞庭湖水面面积一直较小, 城陵矶水位持续偏低, 但受长江来水量影响, 因此有所增长. 6-8 月,洞庭湖水面面积迅速增大, 同时城陵矶 水位迅速上升. 这一时期, 长江中下游持续少雨的态势迅速转变, 降水增加, 形成了旱涝急转的局面 ${ }^{[29]} .9$ 月 以后洞庭湖水面面积逐渐减小, 城陵矶水位也逐渐降低. 这是由于降水结束后, 长江来水量减少, 洞庭湖出 湖水量大于人湖水量, 水面范围逐渐缩小, 城陵矶水位也逐渐降低. 可以发现, 2002 和 2011 年, 长江与洞庭 湖同时经历丰水年份与偏枯年份.

分别将 2002 与 2011 年东洞庭湖月平均水面面积与城陵矶月平均水位进行拟合, 得到二者的绳套关系 曲线, 相关系数分别为 0.943 和 0.885 . 对比 2002 和 2011 年东洞庭湖水面面积与城陵矶水位的绳套关系曲 线、2002 和 2011 年洞庭湖水面面积与城陵矶水位的绳套关系曲线, 可以发现二者形状极为相似,但东洞庭 湖水面面积与城陵矶水位的相关系数更高. 将 2002 和 2011 年洞庭湖水面面积与城陵矶水位绳套关系曲线 分别与 2000-2012 年洞庭湖水面面积与城陵矶水位多年平均绳套关系曲线对比, 可以发现 2002 年绳套关 系曲线较为规则, 与 2000-2012 年多年平均绳套关系曲线相似 (图 5B) : 在枯水期洞庭湖水面面积大于拟合 值, 曲线偏向上; 在涨水期间, 水面面积小于拟合面积, 曲线偏向下; 在丰水期间, 水面面积达到最大值, 水面 面积大于拟合值, 曲线偏向上; 在退水期间, 水面面积小于拟合面积, 曲线相对偏下. 2011 绳套关系曲线较为 不规则, 形成一环套一环的复杂曲线. 在丰水年 (2002 年) 或干早年 (2011 年), 城陵矶水位与洞庭湖水面面 积变化的相关性仍然较高,东洞庭湖水面面积与城陵矶水位的相关性比洞庭湖的更高.

\section{5 结论}

1) 从时间变化上看, 洞庭湖水面面积年内变化呈现规律性涨落, 具有明显的涨 (4-6月)-丰 (7-9 月)枯 (1-3 月) -退 (10-12 月) 的水文节律, 具体表现为丰水期水面连成一片, 枯水期仅存几条带状水域的季 节性变化特征; 从空间变化上来看, 洞庭湖水面面积的增长是由湖体中心向外增长扩大, 东洞庭湖增长面积 最多, 南洞庭湖次之, 西洞庭湖面积增长最少, 洞庭湖年平均水面面积的减少是由外向湖体中心逐渐减小, 东洞庭湖减少最多,南洞庭湖次之,西洞庭湖减少最少.

2) 2000-2012 年洞庭湖水面面积变化与城陵矶水位变化相关性较高, 相关系数为 0.878 . 洞庭湖水面面 积与城陵矶水位的绳套关系曲线呈现为 3 个环形相连接, 每 4 个月份形成一个小环形. 在枯水期、涨水期、 丰水期、退水期,水位相同时, 水面面积存在差异, 水面面积相同时, 对应不同的水位. 2000-2012 年东洞庭 湖水面面积与城陵矶水位月平均绳套曲线的相关系数为 0.937 , 东洞庭湖水面面积的变化同样具有涨-丰 枯-退的水情,并且在涨水期、退水期面积变化较大.

3) 2000- 2012 年间, 洞庭湖水面面积变化与城陵矶水位的相关性在枯水期较低, 为 0.291 , 丰水期最高, 为 0.853 , 涨水期和退水期相关性较高, 分别为 0.700 和 0.744 . 由于洞庭湖水情具有季节性变化特征, 洞庭湖 水面面积与城陵矶水位的关系也较为复杂. 2000-2012 年间, 东洞庭湖水面面积与城陵矶水位在相关性在 枯水期、涨水期、丰水期和退水期分别为 $0.138 、 0.773 、 0.794$ 和 0.763 . 存在一定的因素影响洞庭湖水面面积 变化与城陵矶水位的关系: 枯水期、丰水期长江来水量对洞庭湖水面面积与城陵矶水位的绳套关系影响较 大, 对东洞庭湖水面面积与城陵矶的绳套关系影响更为显著; 涨水期、退水期东洞庭湖面积的变化对洞庭湖 水面面积与城陵矶的绳套关系存在一定的影响.

4) 在城陵矶水位低于 $24 \mathrm{~m}$ 或高于 $30 \mathrm{~m}$ 时,洞庭湖水面面积变化较小. 城陵矶水位介于 $24 \sim 30 \mathrm{~m}$ 时, 洞 庭湖水面面积变化较大. 也即在涨水期、退水期, 洞庭湖水面面积变化大, 在枯水期、丰水期, 洞庭湖水面面 积变化较小. 东洞庭湖水面面积变化与洞庭湖水面面积变化规律一致, 并且东洞庭湖水面面积与城陵矶水 位之间的相关性在涨水期、退水期高于整个湖区水面面积与城陵矶之间的相关性.

5) 在干旱年 (2011 年) 与丰水年 (2002 年), 城陵矶水位与洞庭湖水面面积变化的相关性仍然较高, 分 别为 0.834 和 0.940 , 东洞庭湖水面面积的变化与城陵矶水位的相关性更高, 分别为 0.885 和 0.943 . 丰水年 洞庭湖水面面积变化与城陵矶水位的拟合结果比枯水年的拟合结果更好, 在丰水期洞庭湖水面面积与城陵 
矶水位的拟合结果也比枯水期的拟合结果更好.

\section{6 参考文献}

[ 1 ] Lu Jinyou, Luo Hengkai. Preliminary analysis on variation of the relation between Yangtze River and Dongting Lake. Yangtze River, 1999, 30(4) : 24-26. [卢金友, 罗恒凯. 长江与洞庭湖关系变化初步分析. 人民长江, 1999, 30(4): 24-26.]

[ 2 ] Huang S, Li J, Xu M. Water surface variation monitoring and flood hazard analysis in Dongting Lake area using long-term Terra/MODIS data time series. Nat Hazards, 2012, 62: 93-100.

[ 3 ] Kameyama Satoshi, Zhang Jiqun, Wang Qinxue et al. An approach to estimate the water level and volume of Dongting Lake using Terra/MODIS Data. Acta Geographica Sinica, 2004, 59(1): 88-94. [龟山哲, 张继群, 王勤学等. 应用 Terra/ MODIS 卫星数据估算洞庭湖蓄水量估算. 地理学报, 2004, 59(1) : 88-94.]

[ 4 ] Cai Qing, Huang Lu, Liang Jie et al. Estimation of the water volume of the Dongting Lake with TERRA/MODIS date. Journal of Hunan University (Natural Sciences), 2012, 39(4) : 64-69. [ 蔡青, 黄璐, 梁婕等. 基于 MODIS 遥感影像数 据的洞庭湖蓄水量估算. 湖南大学学报 (自然科学版), 2012, 39(4) : 64-69.]

[ 5 ] Hayashi S, Murakami S, Xu K et al. Effect of the Three Gorges Dam Project on flood control in the Dongting Lake area, China, in a 1998-tyoe flood. Journal of Hydro-environment Research, 2008, 2 (3) : 148-163.

[ 6 ] Ning Lei. A study on river-lake relationship and flood control situation of the middle Yangtze River [Dissertation]. Wuhan: Wuhan University, 2010: 1-132. [宁否. 长江中游江湖关系与防洪形式研究 [学位论文]. 武汉: 武汉大学, 2010: 1-132.]

[ 7 ] Sun Z, Huang Q, Christian OPP et al. Impacts and implications of major changes causes by the Three Gorges Dam in the middle reaches of the Yangtze River, China. Water Resour Manage, 2012, 26: 3367-3378.

[ 8 ] Hu Guangwei, Mao Dehua, Li Zhengzui et al. Research overview on the influence of the Three Gorges project construction on Dongting Lake. Journal of Natural Disasters, 2013, 22(5): 44-52. [ 胡光伟, 毛德华, 李正最等. 三峡工程建设对 洞庭湖的影响研究综述. 自然灾害学报, 2013, 22(5): 44-52.]

[ 9 ] Wan Rongrong, Yang Guishan, Wang Xiaolong et al. Progress of research on the relationship between the Yangze River and its connected lakes in the middle reaches. J Lake Sci, 2014, 26(1) : 1-8. DOI:10.18307/2014.0101. [万荣荣, 杨 桂山, 王晓龙等. 长江中游通江湖泊江湖关系研究进展. 湖泊科学, 2014, 26(1): 1-8.]

[10] Lai X, Liang Q, Jia H et al. Impoundment effects of the Three-Gorges-Dam on flow regimes in two China's largest freshwater lakes. Water Resour Manage, 2014, 28: 5111-5124.

[11] Zhan L, Chen J, Zhang S et al. Relationship between Dongting Lake and surrounding rivers under the operation of the Three Gorges Reservoir, China. Isotopes in Environment and Health Studies, 2015, 51(2) : 255-270.

[12] Hu C, Fang C, Cao W. Shrinking of Dongting Lake and its weakening connection with the Yangtze River: Analysis of the impact on flooding. International Journal of Sediment Research, 2015: 256-262.

[13] Chen Jin, Huang Wei. Flood control function of river-connecting lakes on the middle and lower reaches of Changjiang River. Journal of China Institute of Water Resources and Hydropower Research, 2005, 3(1): 11-15. [ 陈进, 黄薇. 通江湖泊 对长江中下游防洪的作用. 中国水利水电科学研究学报, 2005, 3(1) : 11-15.]

[14] Lai Xijun, Jiang Jiahu, Huang Qun. Pattern of impoundment effects and influencing mechanism of Three Gorges Project on water regime of Lake Dongting. J Lake Sci, 2012, 24(2) : 178-184. DOI:10.18307/2012.0202. [赖锡军, 姜加虎, 黄 群. 三峡工程蓄水对洞庭湖水情的影响格局及其作用机制. 湖泊科学, 2012, 24(2): 178-184.]

[15] Li Jingbao, Zhou Yongqiang, Ou Chaomin et al. Evolution of water exchange ability between Dongting Lake and Yangtze River and its respond to operation of the Three Gorges Reservior. Acta Geographica Sinica, 2013, 68(1) : 108-177. [李景 保, 周永强, 欧朝敏等. 洞庭湖与长江水体交换能力演变及对三峡水库运行的响应. 地理学报, 2013, 68(1): 108-177.]

[16] Huang Q, Sun Z, Christian OPP et al. Hydrological drought at Dongting Lake: Its detection, characterization, and challenges associated with Three Gorges Dam in Central Yangtze, China. Water Resour Manage, 2014, 28: 5377-5388.

[17] Lai X, Liang Q, Huang Q et al. Numerical evaluation of flow regime changes induced by the Three Gorges Dam in the Middle Yangtze. Hydrology Research, 2016: 1-12. DOI: 10.2166/nh.2016.158.

[18] Song Qiuming, Xiong Lihua, Xiao Yi et al. Study on relationship between lake area and water level of Dongting Lake based on MODIS images. Water Saving Irrigation, 2011, 6: 20-26. [ 宋求明, 熊立华, 肖义等. 基于 MODIS 遥感影像的洞庭 
湖面积与水位关系研究. 节水灌溉, 2011, 6: 20-26. ]

[19] Li Jinggang, Li Jiren, Huang Shifeng et al. The remote sensing monitoring analysis of Chinese Dongting Lake water area variations in last 10 years using Terra/MODIS date time series. Journal of China Institute of Water Resources and Hydropower Research, 2010, 8(3): 201-207. [李景刚, 李纪人, 黄诗峰等. 近 10 年来洞庭湖湖区水面面积变化遥感监测分 析. 中国水利水电科学研究院学报, 2010, 8(3): 201-207.]

[20] Peng Dingzhi, Xu Gaohong, Hu Caihong et al. Analysis of the influence of Dongting Lake's area variation measured by MODIS on flood level. Yangtze River, 2004, 35(4) : 14-16. [ 彭定志, 徐高洪, 胡彩虹等. 基于 MODIS 的洞庭湖面积 变化对洪水位的影响. 人民长江, 2004, 35(4): 14-16.]

[21] Du Tao, Xiong Lihua, Yi Fanghui et al. Relation of the water area of Dongting Lake to the water levels of hydrological station based on MODIS images. Resources and Environment in the Yangtze Basin, 2012, 21(6): 756-765. [杜涛, 熊立华, 易放辉等. 基于 MODIS 数据的洞庭湖水体面积与多站点水位相关关系研究. 长江流域资源与环境, 2012, 21(6): 756-765. ]

[22] Dou Hongshen, Jiang Jiahu eds. Dongting Lake. Hefei: Press of University of Science and Technology of China, 2000. [窦 鸿身, 姜家虎. 洞庭湖. 合肥: 中国科学技术大学出版社, 2000.]

[23] Peng Yeru. Study on ecological water level and water regime of the Dongting Lake under water volume changes [Dissertation]. Changsha: Hunan University, 2013: 1-70. [彭也茹. 水量变化下洞庭湖生态水位及水情研究 [学位论文]. 长 沙: 湖南大学, 2013: 1-70.]

[24] Xu Gui, Huang Yuxian, Li Xichun et al. Analysis on causes of water level rising at Chenglingji hydrological station of Changjiang River. Journal of Hydraulic Engineering, 2004, 8(6): 33-45. [ 徐贵, 黄玉仙, 黎惜春等. 城陵矶洪水位抬 高原因分析. 水利学报, 2004, 8(6): 33-45.]

[25] Liu Yujie, Yang Zhongdong eds. Principle and algorithm of MODIS remote sensing information processing. Beijing: Science Press, 2001. [刘玉洁, 杨忠东. MODIS 遥感信息处理原理与算法. 北京: 科学出版社, 2001.]

[26] Jiang G, Han B, Gao Y et al. Review of 40-year earth observation with Landsat series and prospects of LDCM. Journal of Remote Sensing, 2013, 17(5) : 1033-1048.

[27] Wiliams DL, Goward S, Arvidson T. Landsat: Yesterday, today, and tomorrow. Photogrammetric Engineering and Remote Sensing, 2006, 72(10): 1171-1178.

[28] Mc Feeters SK. The use of the Normalized Difference Water Index ( NDWI) in the delineation of open water feature. International Journal of Remote Sensing, 1996, 17(7) : 1425-1432.

[29] Ji Hongxia, Fan Xingwang, Wu Guiping et al. Accuracy comparison and analysis of methods for water area extraction of discrete lakes. J Lake Sci, 2015, 27(2) : 327-334. DOI:10.18307/2015.0218. [吉红霞, 范兴旺, 吴桂平等. 离散型 湖泊水体提取方法精度对比分析. 湖泊科学, 2015, 27(2): 327-334.]

[30] Liu Y, Song P, Peng J et al. A physical explanation of the variation in threshold for delineating terrestrial water surfaces from multi-temporal images: Effects of radiometric correction. International Journal of Remote Sensing, 2012, 33(18): 5862-5875.

[31] Li Xiaojuan, Gong Zhaoling, Liu Xiaomeng eds. ENVI remote sensing image processing tutorial. Beijing: China Environment Science Press, 2007. [李晓娟, 宫兆玲, 刘晓萌. ENVI 遥感影像处理教程. 北京: 中国环境科学出版 社, 2007.]

[32] Dai Xue, Wan Rongrong, Yang Guishan et al. Temporal variation of hydrological rhythm in Poyang Lake and the associated water exchange with the Changjiang River. Scientia Geographica Sinica, 2014, 34(12): 1488-1496. [戴雪, 万荣荣, 杨 桂山等. 鄱阳湖水文节律变化及其与江湖水量交换的关系. 地理科学, 2014, 34(12) : 1488-1496. ]

[33] Fang Chunming, Zhong Zhengqin. The influence of capacity decrease on flood stages in Dongting Lake and in Yangtze River. Journal of Hydraulic Engineering, 2001, 11: 70-74. [方春明, 钟正琴. 洞庭湖容积减小对洞庭湖与长江洪水位的 影响. 水利学报, 2001, 11: 70-74.]

[34] Shi Xuan, Xiao Weihua, Wang Yong et al. Characteristics and factors of water level variation in the Dongting Lake during the recent 50 years. South-to-North Water Transfers and Water Science \& Technology, 2012, 10(5): 18-22. [史璇, 肖伟 华, 王勇等. 近 50 年洞庭湖水位总体变化特征及成因分析. 南水北调与水利科技, 2012, 10(5): 18-22.]

[35] Tan Xiaoming. The variation characteristics of water level in Dongting Lake. Hunan Hydro \& Power, 2002, 2: 25-26. [ 谭 晓明. 洞庭湖水位变化特性. 湖南水利水电, 2002, 2: 25-26.]

[36] http: //www.envir.gov.cn/info/2002/9/92582.htm. 2002.

[37] http: //www.changsha.gov.cn/xxgk/szfxxgkml/gzdt/zwdt/201302/t20130218_429583.html. 2013. 